\title{
MODELLING AND CONTROL OF TINNING LINE ENTRY SECTION USING NEURAL NETWORKS
}

\author{
Žilková, J.; Timko, J. \& Girovský, P. \\ Department of Electrical Engineering and Mechatronics, Technical University of Košice, \\ Letná 9, 04200 Košice, Slovakia \\ E-Mail: jaroslava.zilkova@tuke.sk, jaroslav.timko@tuke.sk,peter.girovsky@tuke.sk
}

\begin{abstract}
The objective of this paper is the development of a mathematical model and the design of the control of the drives of a tinning line entry section, using artificial neural networks. The first part of the paper describes the mathematical models of the individual sections of the processing line: a decoiler and four traction rolls joined together by a steel strip creating a flexible linkage. The drive models have been supplemented by neural controllers in such a way as to satisfy the requirements specified for the individual drives and determined by the sheet metal tinning technology. The paper is concluded with a description of the whole model of the tinning line entry section together with the neural controllers and with an evaluation of the achieved simulation results.

(Received in November 2011, accepted in March 2012. This paper was with the authors 1 month for 1 revision.)
\end{abstract}

Key Words: Control, Neural Network, Line Entry Section, Mathematical Model

\section{INTRODUCTION}

Modelling is an effective method enabling the identification of the characteristics of the system under investigation. In real operational conditions, complex dynamic systems, such as the technological line for rolled steel strip treatment described below, can be in various different states. Using simulation we can then experiment with the line model similarly to the real system, without the need to intervene in the real system, eliminating the risk of possible emergency states [1-4].

The continuous process line, the model of which we are going to deal with, is a steel strip tinning line producing tin-plated material used in the packaging industry. It is made up of three autonomous sections [5]:

- the entry section, determined for accumulating a stock of material for the technological section and for reduction of traction in the strip,

- the technological section, where electrolytic tinning of steel sheet takes place, according to the technological formula for particular material options in the Ferrostan process technology,

- the exit section, where coiling of the sheet material takes place.

The entry section of the process line includes the drive of the decoiler device that provides for the decoiling of the strip with the required tension, independent from the coil diameter and the strip speed. The material is welded into an endless strip that follows into the tower accumulator. The subsequent drives of the entry section traction rolls secure the required strip speed. The remaining drives are provided with traction control and secure the required strip tension over its entire length. The galvanic tinning of the steel strip is carried out in the middle section of the process line. The treated strip is then recoiled into coils of the specified diameter and width in the exit section of the line. 
The objective of this paper is the development of the model and the design of the controls of entry section drives using neural networks. As the drives of the technological line under consideration are made up by DC motors, we are in fact dealing with DC motor control using neural networks. The first part of this paper deals with the mathematical model of the individual tinning line entry section drives, followed by description of the linking of the drives applying a flexible linkage model, and then by the development of the complete model of the line entry section. The second part is aimed at the design and implementation of neural controllers used for controlling the speed of the DC motors. In the final part the neural controller properties are compared to the properties of PI controllers.

\section{MATHEMATICAL MODEL OF LINE ENTRY SECTION}

The purpose of the entry section of the line is to create an endless strip of material and secure its stock, enabling continuous operation of the line also during replacement of coils of material at line entry. The individual drives have to meet the requirement of being able to adjust the demanded traction in the strip also at zero speed during strip welding, and to keep it at the required value not only at constant speed but also at start-up and at strip slow down. The entry section of the line has to be capable of generating a speed higher than the speed of the middle - technological section, in order that there is always sufficient stock of material in the tower accumulator. During replenishment of the tower accumulator, the speed of the entry section of the line is increased by $25 \%$ as compared to the speed of the middle - processing section of the line. The principle requirement for the decoiler is to keep a constant traction in the strip both in steady and in dynamic state, therefore the control of the drive has to be aimed at maintaining the traction. The line we modelled did not include a traction sensor, it was therefore necessary to consider indirect control and to determine the traction indirectly from the electrical quantities of the drive.

The mathematical model of the tinning line's entry section is made up of the mathematical models of its individual parts: the decoiler, and traction rolls 1.1 and 1.2 which are linked together by the steel strip creating a flexible linkage. The drives of this line equipment are DC separately excited motors. The mathematical model of the entry section including the controls of the individual drives were based on the requirements for the individual drives that are given by the sheet metal tinning technology specifications. The models of the individual drives were supplemented by models of the controllers, while the parameters of the current controllers were designed according to the optimal module criterion, and the parameters of the speed controllers were designed according to the symmetric optimum criterion.

The mathematical models of the individual drives with DC separately excited motors, which were, together with the proposed controllers modelled in the Matlab/Simulink environment, are shown in the schematics of the relevant decoiler and traction roll models.

\subsection{Decoiler model}

The decoiler mathematical model is shown in Figs. 1 and 2.

Besides controlling current and speed, also indirect control of traction has been applied, which ensures the desired strip tension between the decoiler and traction roll 1.2 both in steady and in dynamic states of the line. Due to dual zone operation, control of current and induced voltage has been implemented in the excitation circuit.

The mathematical model of the decoiler drive armature circuit, shown in Fig.2, beside the decoiler drive model itself also includes computation blocks for the computation of instantaneous coil diameter and instantaneous moment of inertia. 


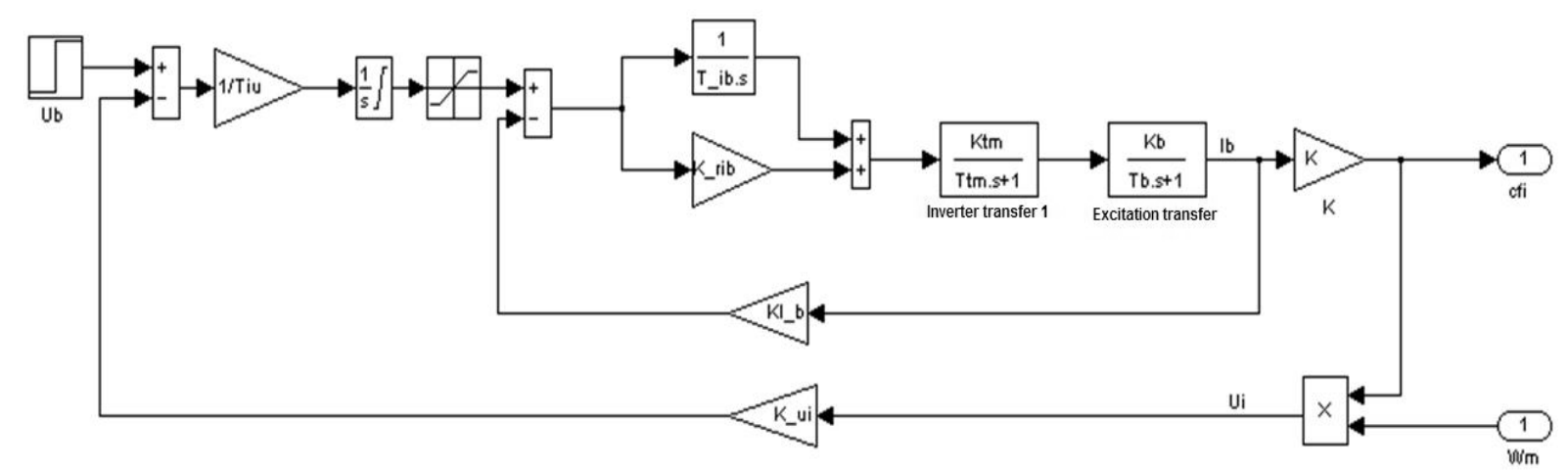

Figure 1: Decoiler mathematical model - excitation circuit.



Figure 2: Decoiler mathematical model - armature circuit.

\subsection{Model of traction roll No. 1.2}

Similarly to the decoiler model, also the model of roll 1.2 is supplemented by indirect traction control which ensures the desired strip tension between the traction rolls (see Fig. 3).

\subsection{Model of traction roll No. 1.1}

Traction roll 1.1 is a speed drive. Its role is to maintain the desired speed of the processing line. For this reason it only contains a current controller with overriding speed control (see Fig. 4). 


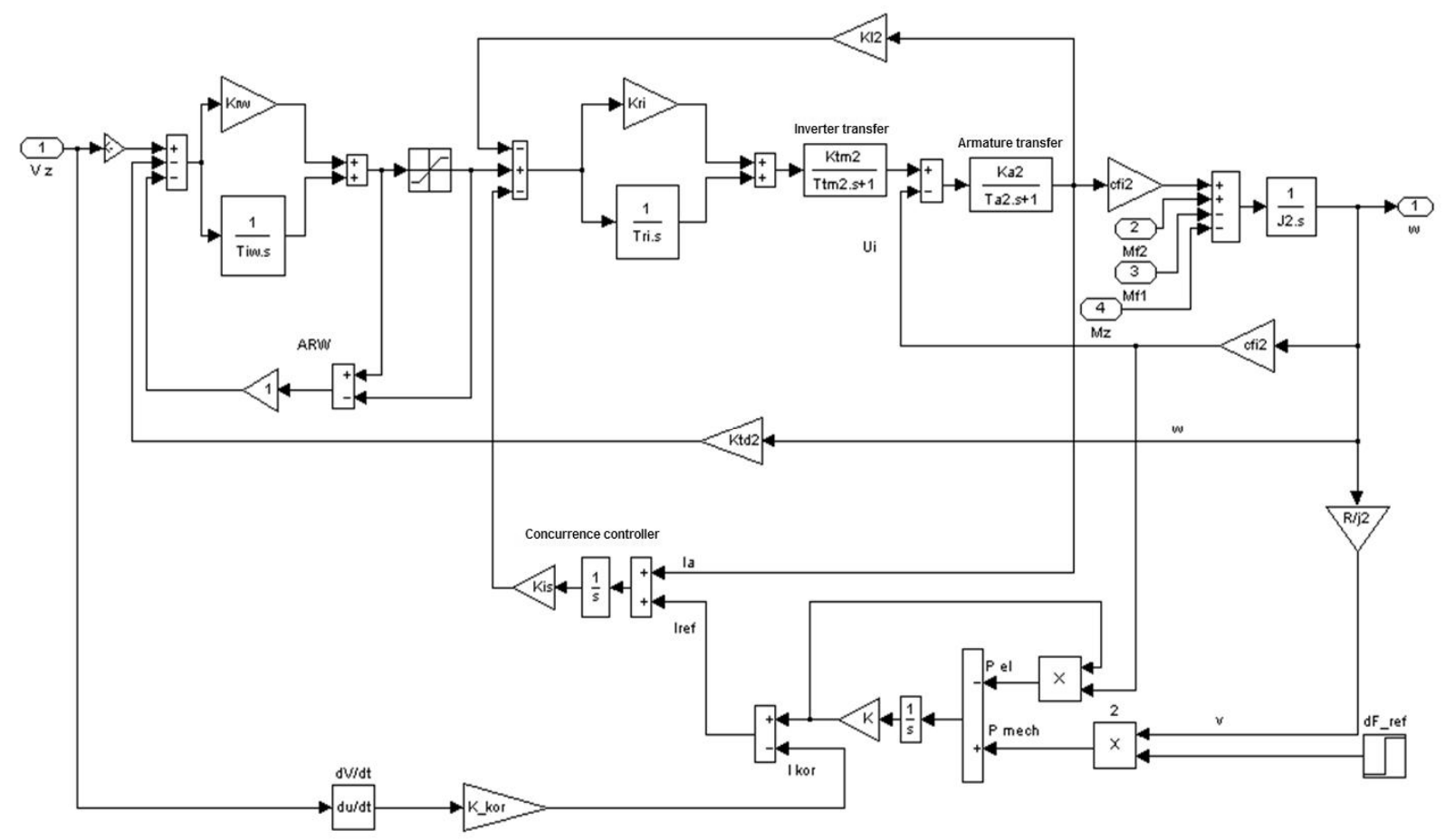

Figure 3: Mathematical model of traction roll 1.2.

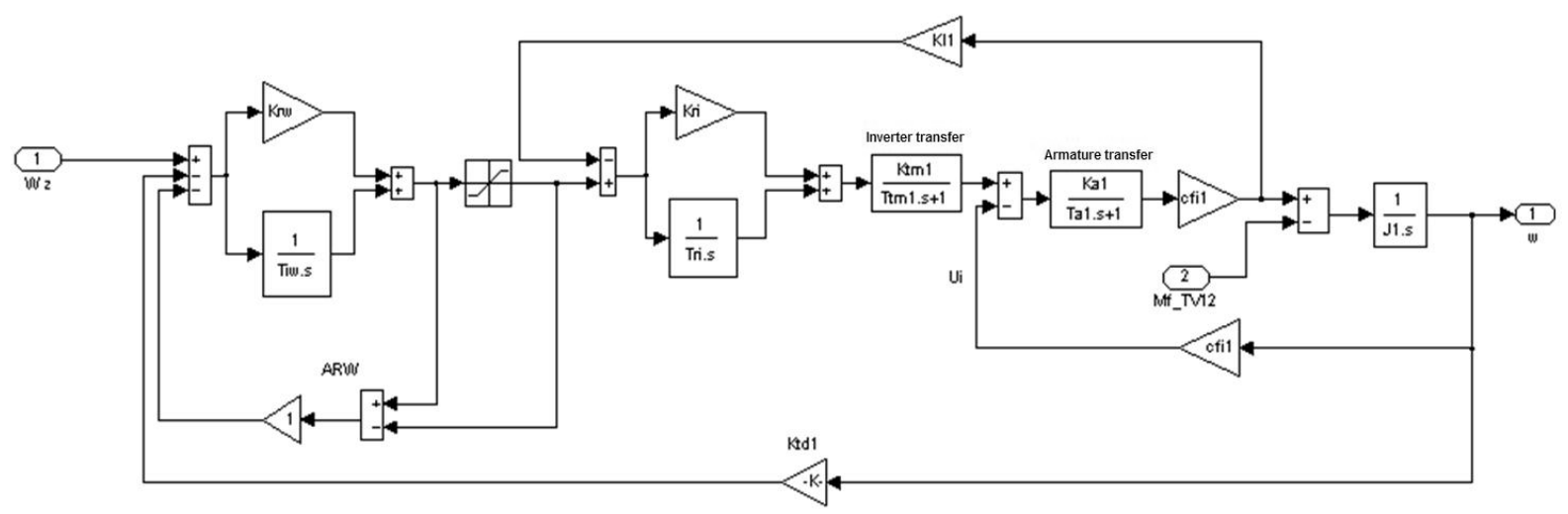

Figure 4: Mathematical model of traction roll 1.1.

\subsection{Mathematical model of line entry section}

The mathematical model of the continuous processing line (Fig. 6) is made up of the models of the individual drives and the model of the strip that creates a flexible linkage between the drives [6, 7]. We have assumed the following simplifications in the system description:

- the material being processed is flexible and the tensile stress value does not exceed the material tensile limit,

- there is friction between the strip and the traction rolls at which no slipping occurs,

- the strip cross-section is constant over the whole length of material,

- no backlash in the transmissions has been considered,

- kinetic energy of the material being processed has not been considered,

- tension in the material is evenly distributed over the whole cross-section.

The entry section line model shown in Fig. 6 was developed by joining the individual models quoted above by means of Hejdis's model [6] of flexible linkage of material in accordance to Fig. 5. 


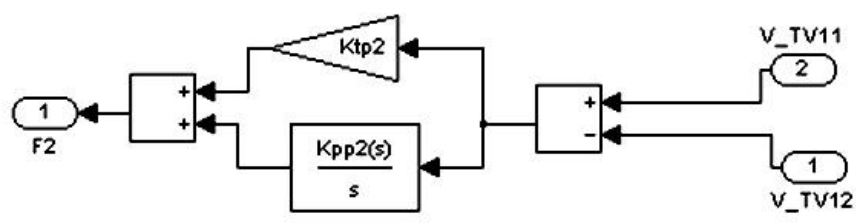

Figure 5: Flexible linkage model.

The flexibility constant $K_{p p}$ does not change between the traction rolls and it is calculated from the sheet metal parameters. This constant change between the decoiler and traction roll 1.2 with coil diameter, therefore it is determined continuously. The damping constant $K_{t p}$ is a percentual value of the flexibility constant:

$$
K_{t p}=(0.01 \ldots 0.1) K_{p p}
$$

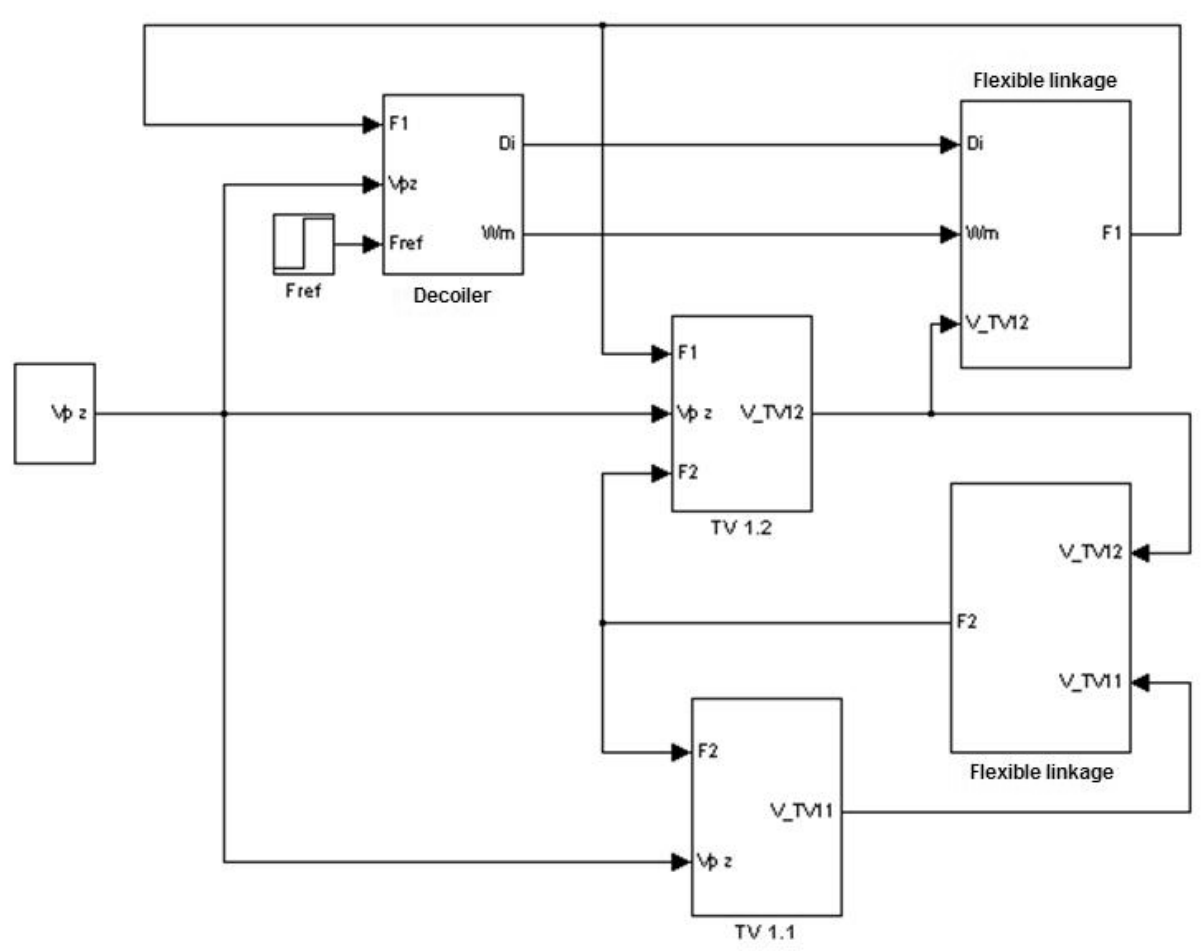

Figure 6: Block diagram of tinning line entry section.

\section{NEURAL CONTROLLER DESIGN}

Similarly to standard motor control, also in this case motor control was achieved through a current controller and a speed controller. An advantage of neural networks is their ability to learn from examples, and the ability of abstraction [8-11], so their applications are useful for electric drives modelling and control [12-16], also.

In the design of DC motor neural-network based control, direct inverse control was applied.

\subsection{Speed controller design}

The speed controlled was developed as an inverse model of the DC motor. The inverse model output is the control voltage value $U_{r}$, while the input is the desired speed $v_{\check{\check{z}}}$ in step „, $k^{\text {“ }}$ and „,k-1“ and the current flowing through the motor in step „,k“, „k-1“ and „k-2“. 


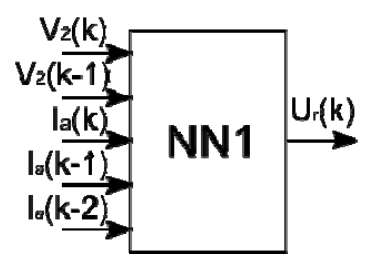

Figure 7: Neural speed controller.

The training set was acquired from the mathematical model of the motor. Various control voltages were applied to the model input at changing loads. From thus obtained data we obtained the direct inverse model of the system shown in Fig. 7, which can be expressed as follows:

$$
u_{r}(k)=f^{-1}\left[\hat{v}(k+1), v_{s}(k), I_{a}(k), I_{a}(k-1), I_{a}(k-2)\right]
$$

The traction roll circumferential velocity value $\hat{v}(k+1)$ was obtained through DC motor simulation. This velocity is not known in control in a closed circuit, it was therefore replaced by the desired speed $v_{z}(k+1)$.

This neural controller controls the speed of the motor without consideration of the current conditions. In order to limit the current, speed control has to be enhanced by current control.

\subsection{Current controller design}

Current control was implemented by means of two neural networks and by limiting. The input into network NN2 is the output from controller NN1 and the real value of circumferential velocity. The output of network NN2 is the current that would be generated in the motor if the control voltage $U_{r}$ were not limited. This current is limited in the following block to the admissible value and network NN3 generates a new control voltage $U_{r o}$, which will not cause current running over the permitted value.

Networks NN1 and NN3 have an identical structure, but have different input signals. Unlike in network NN1, the input into network NN3 is the real value of circumferential velocity and the desired armature current. For network NN2 it applies that:

$$
I_{z}(k)=f^{-1}\left[v_{s}(k), v_{s}(k-1), v_{s}(k-2), u_{r}(k), u_{r}(k-1), I_{z}(k-1)\right]
$$

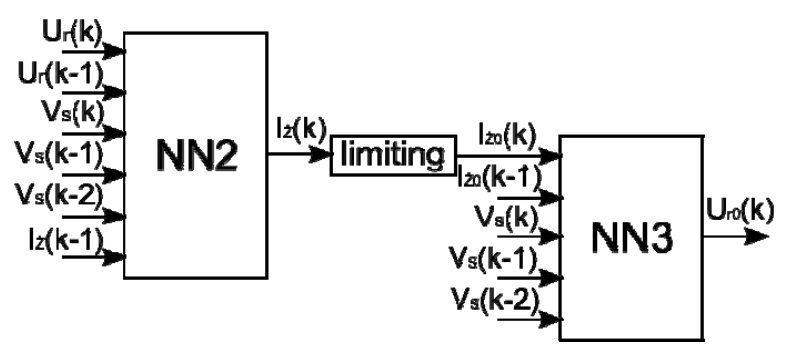

Figure 8: Current control.

Fig. 9 shows a block diagram of speed control with motor current limiting using neural networks.

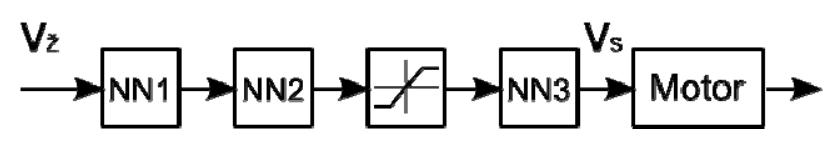

Figure 9: Neural network based speed control with current limiting. 
Networks NN1 and NN3 represent an inverse speed controller and network NN2 is developed as an inverse current controller. Voltage $U_{r}$ which corresponds to the desired speed is brought as the input to neural network NN2. From this voltage and from the real speed $v_{s}$ network NN2 determines the current value corresponding to the desired speed. This current is subsequently limited to the permitted value and neural network NN3 generates control voltage $U_{r}$, which at real speed takes into account the current limitation. Motor speed control is more steady when only current with a value that is proportional to the load torque enters the speed controller. The total current was therefore rectified by the current proportional to the dynamic torque.

In our neural control design we used cascade forward neural networks with tan sigmoid transfer function in the hidden layer and linear transfer function in the output layer. The configuration of networks NN1 and NN3 is [5-9-1], network NN2 [6-9-1] and network NN4 [3-7-1]. All networks operate with a step of $5 \mathrm{~ms}$.

In neural network-based control of line entry section traction roll drives the general control structure is similar to that used in PI controllers. The current and speed feedback controllers were substituted by neural controllers, while the remaining parts of the mathematical model remained unchanged.

Fig. 10 shows a block diagram of traction roll 1.1 model, and Fig. 11 shows a block diagram of traction roll 2.2 mathematical model, using neural controllers.

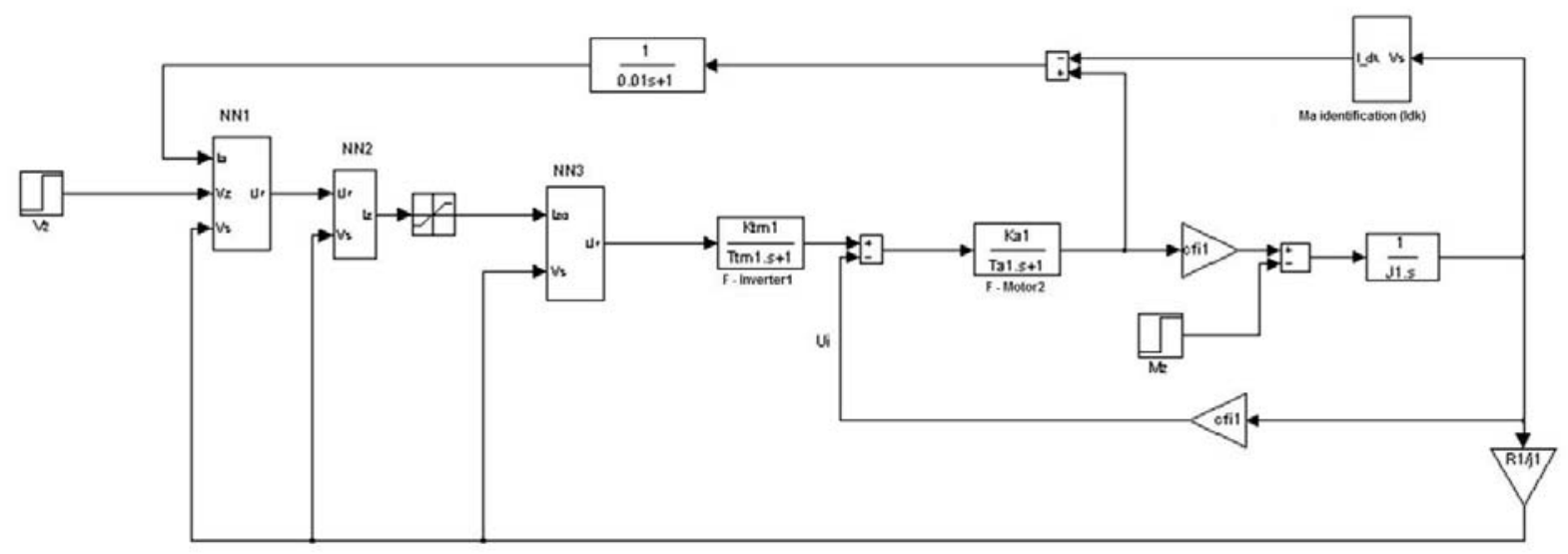

Figure 10: Block diagram of traction roll 1.1 mathematical model.

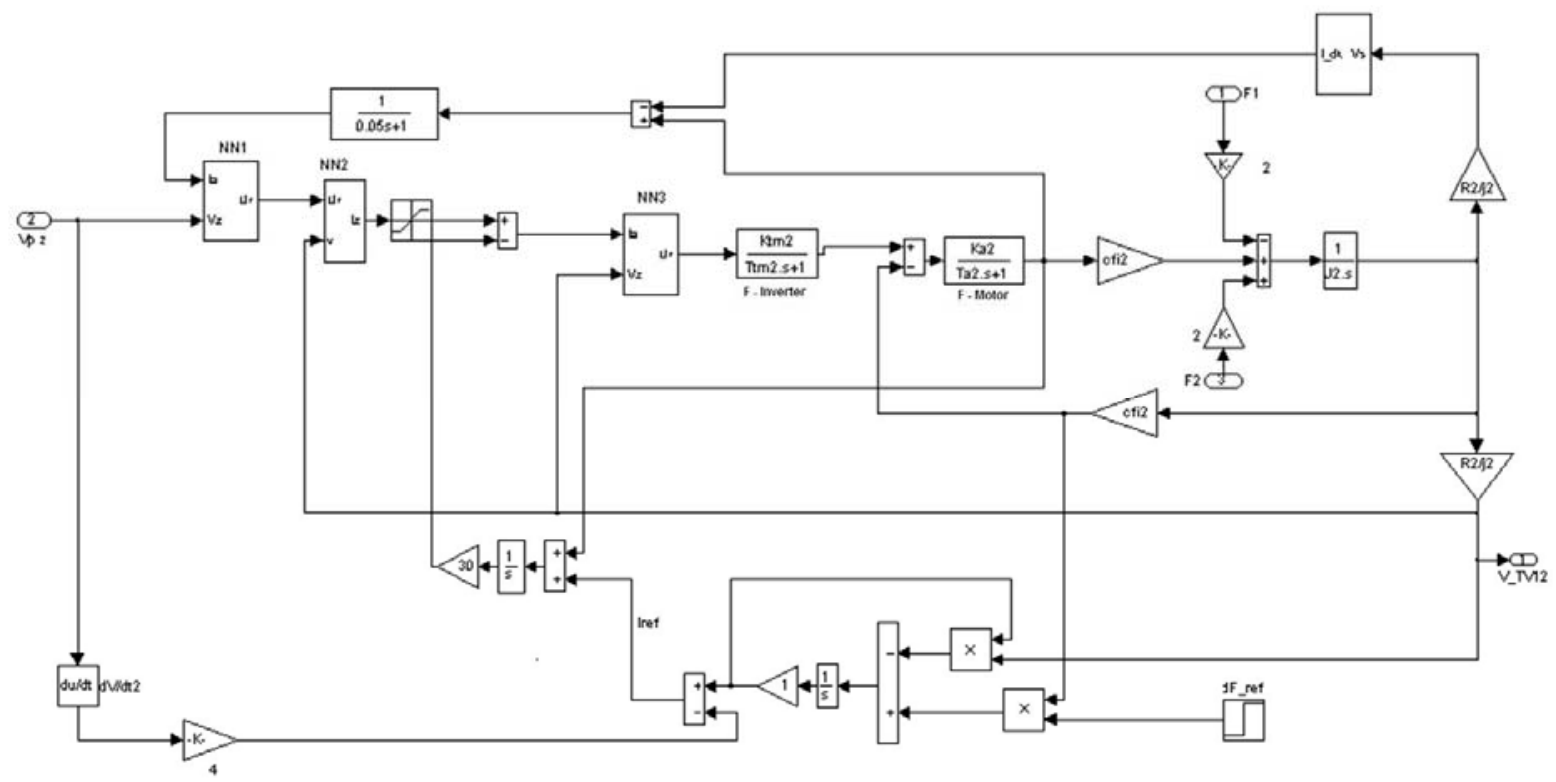

Figure 11: Block diagram of traction rolls No. 1.2 mathematical model with neural controller. 
In the following part of the paper, the courses of selected quantities achieved through simulation of control of individual pieces of equipment and of the whole entry section of the line using PI controllers and using neural networks are specified and compared.

\section{ACHIEVED SIMULATION RESULTS}

In the first part, results of traction roll simulations are presented. As the simulation results for traction rolls 1.1 and 1.2 have the same characteristics, only results for the first traction roll are presented. Also the courses from PI and neural controllers have the same characteristics, therefore in the first part tests of these controllers under varying conditions are presented. Figs. 12 to 16 show the courses of circumferential velocities and armature current of traction roll No.1.1 obtained during PI controller control, compared to the courses obtained during neural controller control.

Fig. 12 presents the course of circumferential velocity of traction roll 1.1 with a neural controller at the desired roll speed of $5 \mathrm{~m} / \mathrm{s}$, where the affect of nominal torque started at the time of $3 \mathrm{~s}$. The start-up in this case was along a ramp. Contrary to the PI controller, in the setup with the neural controller there was no speed overshoot (Fig. 12). Fig. 13 shows the corresponding motor armature current course.

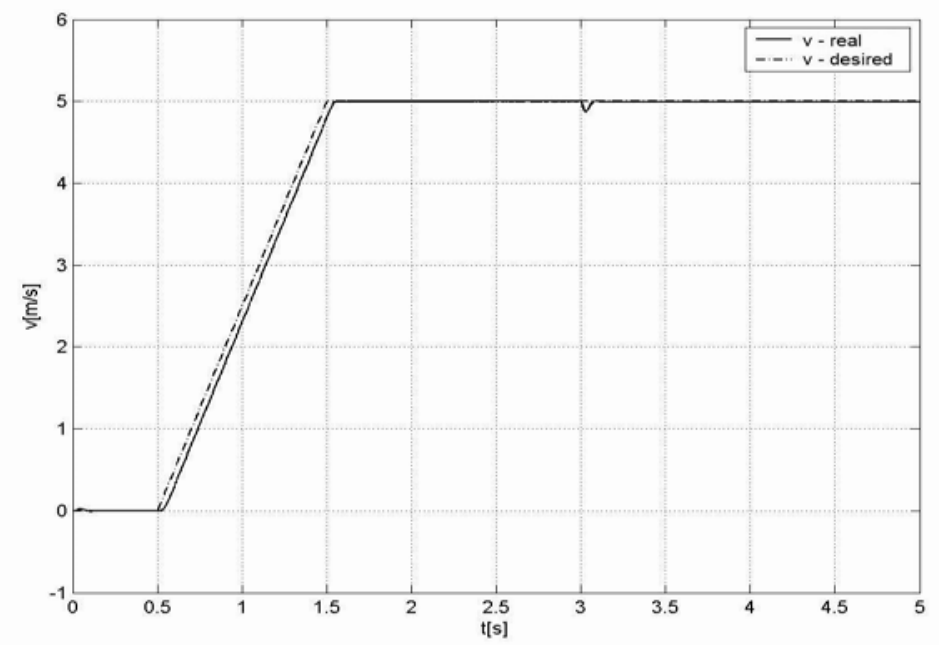

Figure 12: Course of circumferential velocity of traction roll 1.1 with neural controller.

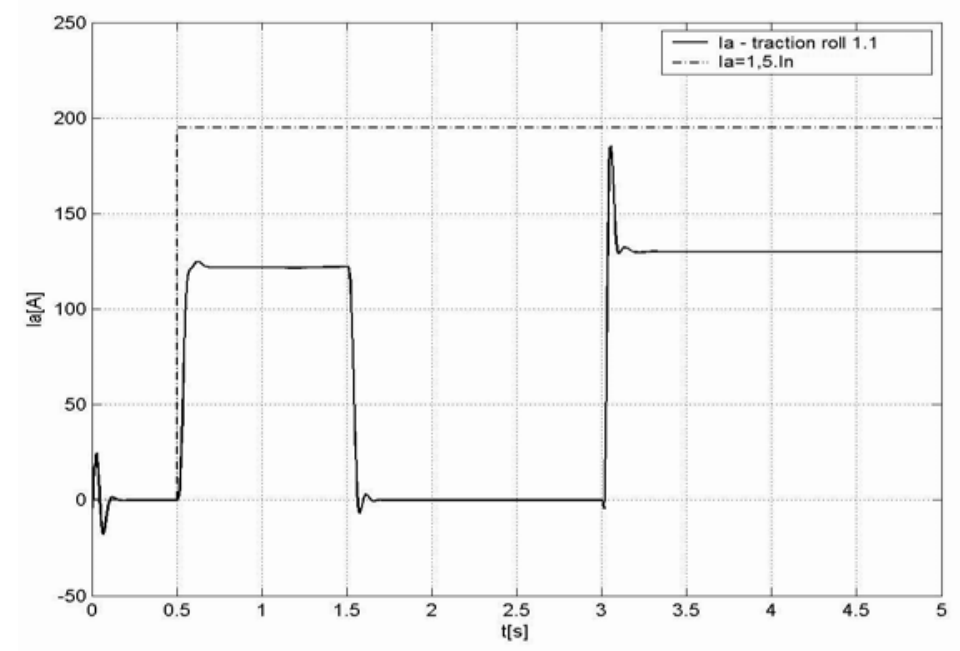

Figure 13: Armature current course in traction roll 1.1 neural controller. 
The following part of the paper summarizes the test results of the whole entry section of the line in accordance with Fig. 6 using PI controllers and neural controllers.

The characteristics of the whole entry section of the line were tested in various operational states, demonstrated on the speed course in Fig. 16:

- line start-up to the speed of $3.2 \mathrm{~m} / \mathrm{s}$ in time $t=(1-3.2) \mathrm{s}$,

- line running at constant speed of $3.2 \mathrm{~m} / \mathrm{s}$ in time $t=(4-8) \mathrm{s}$,

- slow down of line to zero speed in time $t=(8-12) \mathrm{s}$,

- zero speed in time $t=(12-16) \mathrm{s}$,

- line start-up to the speed of $4.5 \mathrm{~m} / \mathrm{s}$ in time $t=(16-20.5) \mathrm{s}$,

- line running at constant speed of $4.5 \mathrm{~m} / \mathrm{s}$ in time $t=(20.5-25) \mathrm{s}$.

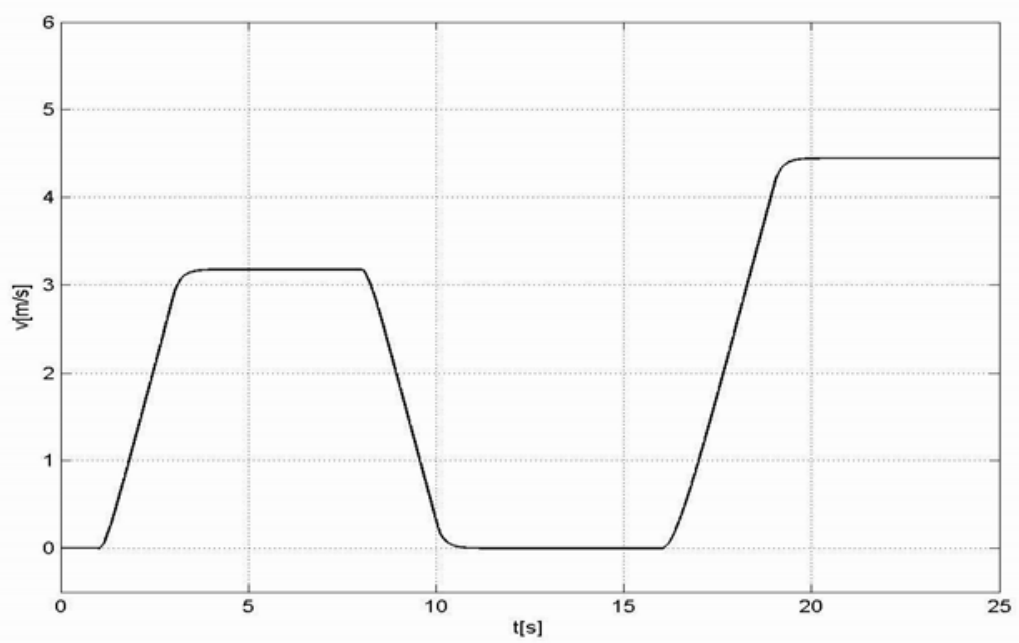

Figure 14: Speed course of the line.

The desired tractive force value in the strip was set at $5000 \mathrm{~N}$. The courses of tractive forces and currents correspond to the course of the desired line speed according to Fig. 14.

The following figures show the tractive force courses between the decoiler and traction roll 1.2 with PI controller (Fig. 15) and with neural controller (Fig. 16).



Figure 15: Tractive force in strip between the decoiler and traction roll 1.2 with PI controller. 


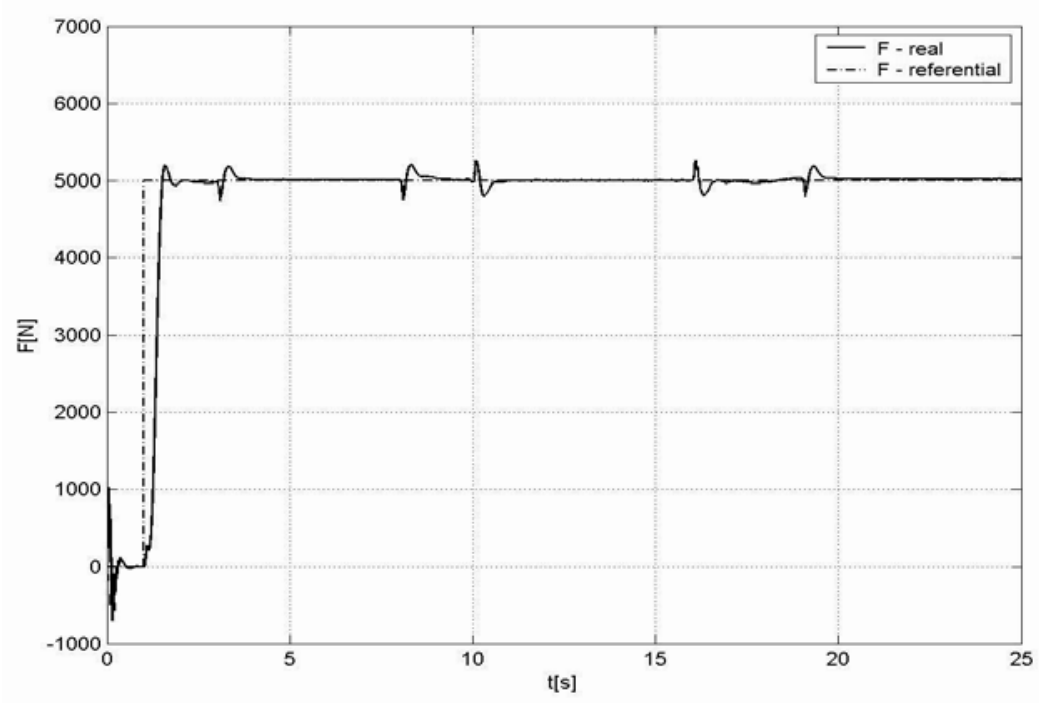

Figure 16: Tractive force in strip between the decoiler and roll 1.2 with neural controller.

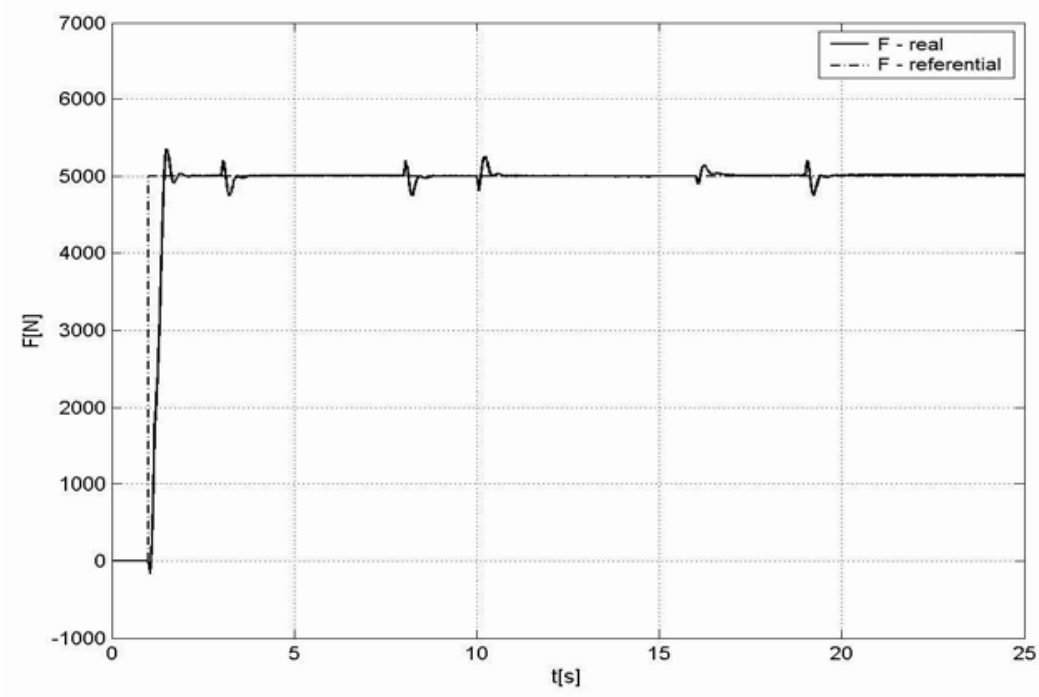

Figure 17: Tractive force between traction rolls 1.2 and 1.1 with PI controller.

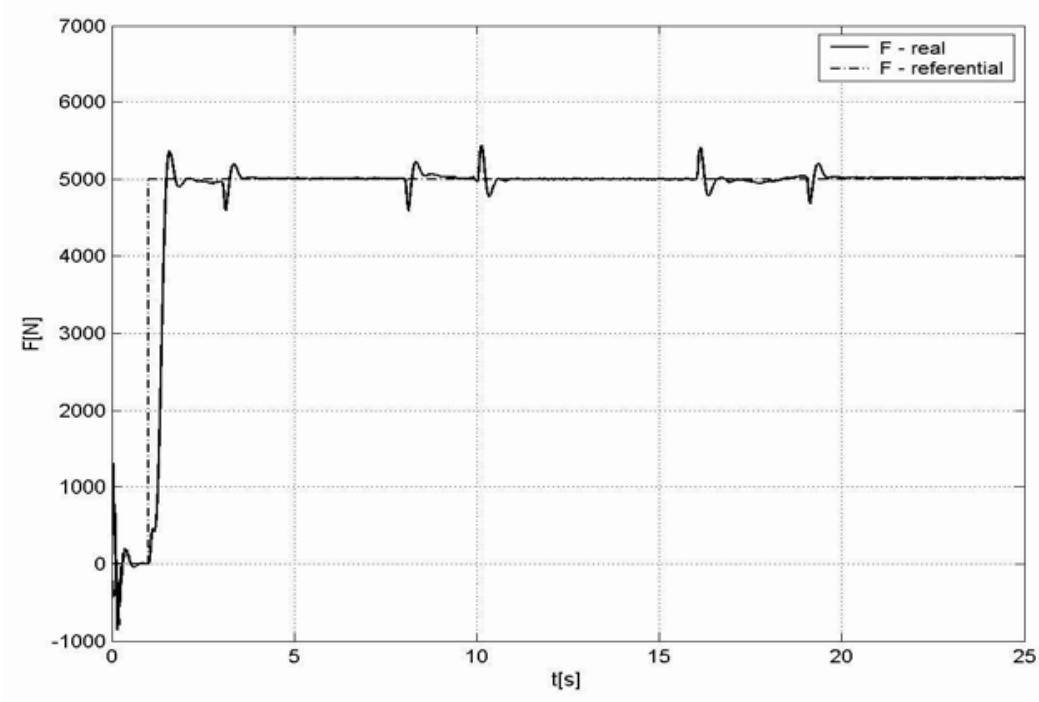

Figure 18: Tractive force between traction rolls 1.2 and 1.1 with neural controller. 
Figs. 17 and 18 show the tractive force with PI controller (Fig. 17) and neural controller (Fig. 18), between traction rolls 1.2 a 1.1.

Figs. 19 and 20 show armature currents of the decoiler and traction roll 1.1 and 1.2 drives with PI controller (Fig. 19) and neural controllers (Fig. 20).

The courses of current show what the operational states of the individual drives are if the line speed changes according to Fig. 16.

During all states of the line, the decoiler is in generator mode and it represents a braking mechanism. At constant strip speed the braking current magnitude is proportional to the tractive force magnitude in the strip. During line start-up, this current is decreased by the current which is proportional to the dynamic torque. During slowdown of the line the inertial masses need to be braked down, therefore the braking current needs to be increased.

When the tractive force of the individual sections is the same, the traction roll 1.2 drive operates at constant speed and it is not loaded. During slowdown of the line the inertial masses need to be braked, therefore the drive passes from motor to generator mode.

The drive of traction roll 1.1 operates in motor run during all line states. The current magnitude at constant strip speed is proportional to the tractive force in the strip in the section between the traction rolls. During start-up or deceleration of the line the current needs to be increased or reduced by the value proportional to the dynamic torque.

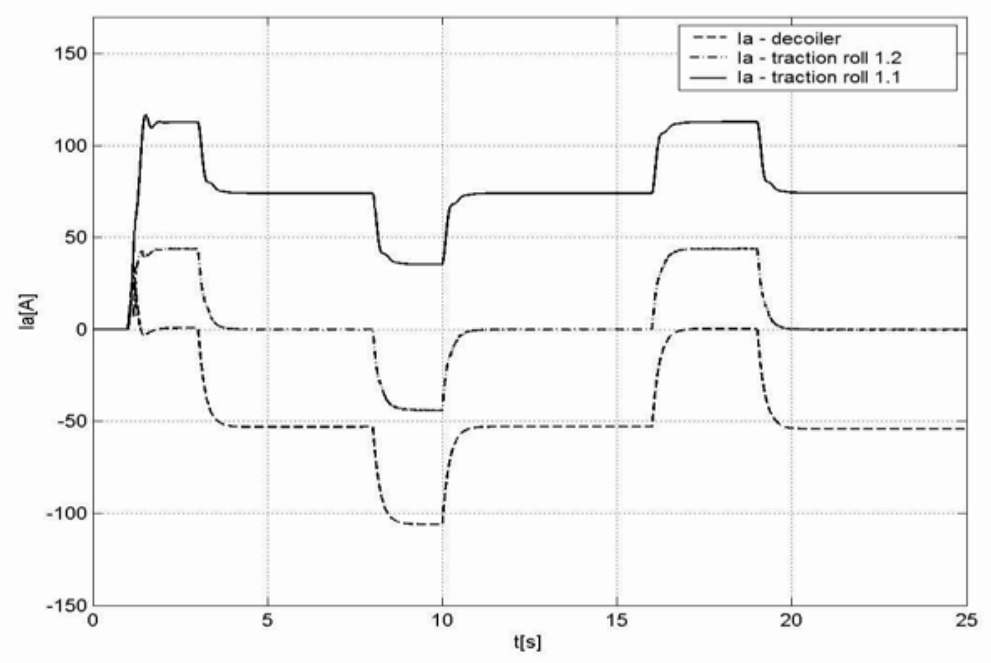

Figure 19: Armature currents of drives with PI controller.

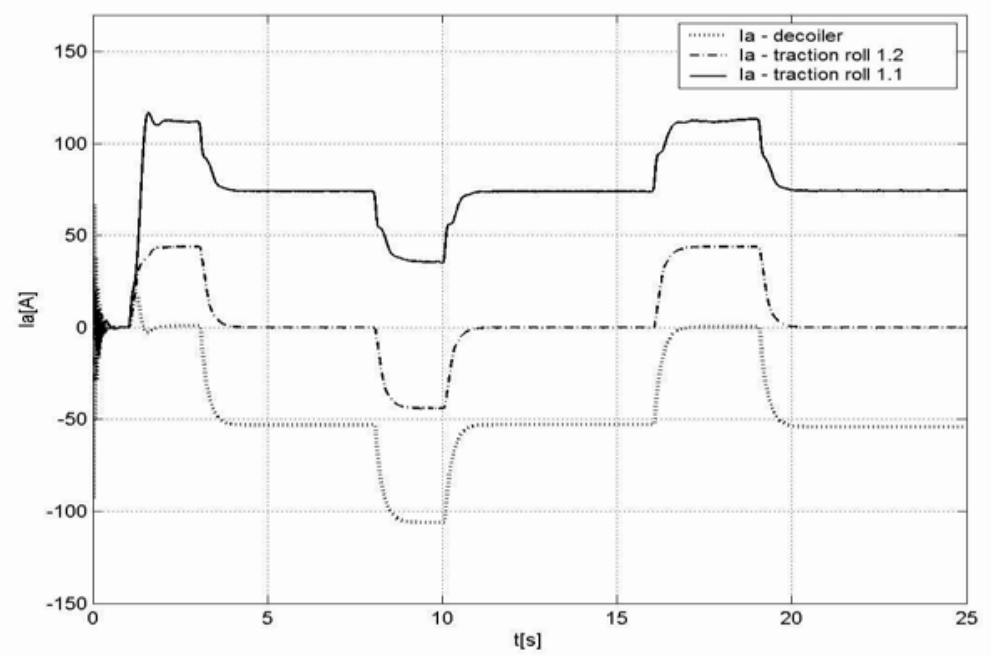

Figure 20: Armature currents of drives with neural controller. 


\section{CONCLUSION}

Our objective was to develop a model of a complex dynamic system - a processing line drive control - that would improve standard solutions, and to demonstrate at the same time the possibilities of artificial intelligence methods application. Through simulation it is possible to experiment with the developed model similarly to experimenting with a real system, without the necessity of intervening into the real system and thus eliminating the risk of possible emergency states. As the simulations show, the characteristics of neural networks-based control are similar to standard control methods, while the assets of neural networks application can be seen mainly in the solution of real problems, where the measured quantities are influenced by interference. In such cases neural networks, compared to other methods, are able to better estimate the performance of the original approximated function. The advantages of neural networks application are manifested mainly in the modelling of complex systems where they allow, with a high degree of precision, the approximation of any continuous function without the knowledge of the structure of the system to which they are applied. A great advantage of neural networks is their ability to learn from examples and to capture nonlinear dependencies, as well as the ability of abstraction, i.e. ability to respond to a certain set of input samples and not only to training samples from this set.

\section{ACKNOWLEDGEMENT}

The authors wish to thank for the support to the R\&D operational program Centre of excellence of power electronics systems and materials for their components II. No. OPVaV2009/2.1/02-SORO, ITMS 26220120046 funded by European regional development fund (ERDF).

\section{REFERENCES}

[1] Nitu, E.; Iordache, M.; Marincei, L.; Charpentier, I.; Le Coz, G.; Ferron, G.; Ungureanu, I. (2011). FE-modeling of cold rolling by in-feed method of circular grooves, Strojniski vestnikJournal of Mechanical Engineering, Vol. 57, No. 9, 667-673, doi:10.5545/sv-jme.2010.244

[2] Timko, J.; Žilková, J; Girovský, P. (2009). Modelling and control of electrical drives using neural networks, C-Press, Košice, (in Slovak), 202 pages

[3] Hackenschmidt, R.; Alber-Laukant, B.; Rieg, F. (2011). Simulating nonlinear materials under centrifugal forces by using intelligent cross-linked simulations, Strojniski vestnik - Journal of Mechanical Engineering, Vol. 57, No. 7-8, 531-538, doi:10.5545/sv-jme.2011.013

[4] Sliskovic, D.; Grbic, R.; Hocenski, Z. (2011). Online data preprocessing in the adaptive process model building based on plant data, Technical Gazette, Vol. 18, No. 1, 41-50

[5] NN. (1999) Company documentation ARTEP VSŽ, k. p. Košice

[6] Hejdiš, J. (1979). Control of continual line drives with velocity and tensions measure, Electrotechnical Journal, No. 4, 269-279

[7] Brandenburg, G. (1973). Ein mathematisches modell fur eine durchlaufende Stoffbahn in einen System angetriebener umschlumgener Walzen. Regelungstechnik und Prozessdatenverarbeitung, Vol. 21, No. 3, 69-104

[8] Warwick, K.; Irwin, G. W.; Hunt, K. J. (1992). Neural networks for control and systems, P. Peregrinus Ltd., London, United Kingdom

[9] Levin, A. U.; Narendra, K. S. (1993). Control of Nonlinear Dynamical Systems Using Neural Networks: Controllability and Stabilization, IEEE Transactions on Neural Networks, Vol. 4, 192206, doi:10.1109/72.207608 
[10] Levin, A. U.; Narendra, K. S. (1996). Control of Nonlinear Dynamical Systems Using Neural Networks - Part II: Observability, Identification and Control, IEEE Transactions on Neural Networks, Vol. 7, 30-42, doi:10.1109/72.478390

[11] Hagan, M. T.; Demuth, H. B.; De Jesús, O. (2002). An introduction to the use of neural networks in control systems, International Journal of Robust and Nonlinear Control, Vol. 12, 959-985, doi:10.1002/rnc.727

[12] Žilková, J. (2001). Artificial neural networks in process control, Mercury-Smekal, Košice, 50 pages

[13] Vas, P. (1999). Artificial-Intelligence-based electrical machines and drives, Oxford University Press, Oxford

[14] Timko, J.; Žilková, J.; Balara, D. (2002). Artificial neural networks applications in electrical drives, Calypso s.r.o.2002, Košice, (in Slovak), 239 pages

[15] Tudorache, T.; Roman, C. (2010). The numerical modelling of transient regimes of diesel generator sets, Acta Polytechnica Hungarica, Vol. 7, No. 2, 39-53

[16] Dahunsi, O. A.; Pedro, J. O.; Nyandoro, O. T. (2010). System identification and neural network based PID control of servo hydraulic vehicle suspension system, Transactions of the South African Institute of Electrical Engineers, Vol. 101, No. 3, 93-105

Welcome to the 23rd DAAAM Intemational World Symposium

University of Zadar, 2012-Oc tober-24/27

organized under auspices of

\section{Danube Rectors' Conference \& The Rectors' Honor Committee of DAAAM} Intemational for 2012

The 23rd DAAAM

Intemational Symposium

Intelligent Manufacturing

$\&$ Automation: Focus on

Susta ina bility

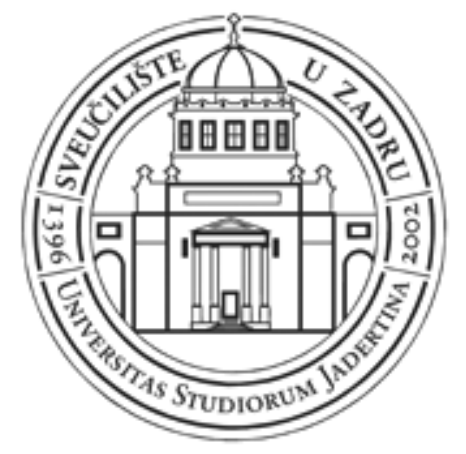

organized by
The $6^{\text {th }}$ European

DAAAM Intemational

Young Researchers' and

Scientists' Conference

DAAAM Intemational Vienna / Universitas Studionum J adertina - University of Zadar / Intemational Academy of Engineering / Vienna University of Technology / Austrian Society of Engineers and Architects - ÖIAV 1848 / University of Applied Sciences - Technikum 